\title{
Single Period Production Problem with SCRAP AND REWORK
}

\author{
Fatemeh Charkhsaz ${ }^{1}$ and Alireza Haji ${ }^{2}$ \\ ${ }^{1} \mathrm{PhD}$ candidate, School of Mathematical and Physical Sciences, the University of \\ Newcastle, Newcastle, Australia \\ fatemeh.charkhsaz@uon.edu.au \\ ${ }^{2}$ Associate Professor, Industrial Engineering Department, Sharif University of \\ Technology, Azadi Ave., Tehran, Iran \\ ahajiesharif.edu
}

\begin{abstract}
The classical single period problem (SPP) has wide use especially in service industries which constitute a great part of the economy. In this paper, a single period production problem is considered as a specific type of SPP. This SPP model is developed by considering the probability of scrap and rework in production at the beginning and during the period. Then, optimal solution is obtained in order to maximize the expected value of total profit. In case of producing the scrap items and defective items, which need rework, the optimal profit of system in comparison to ideal production system reduces. In addition, reduction of profit is more sensitive by increasing the probability of producing scrap items in comparison to the probability of producing defective items. These results would help managers in order to make appropriate decisions on changing or revising machines or technologies.
\end{abstract}

\section{KEYWORDS}

Single Period Problem, Single Period Production Problem, Scrap, Rework, and Defective

\section{INTRODUCTION}

The classical single period problem (SPP) is to find a product's order quantity that maximizes the average profit under probabilistic demand. The SPP model assumes that if any inventory remains at the end of the period, a discount is applied to sell it or dispose it off. If the quantity of order is smaller than the realized demand, the news-vendor loses some profit [1].

The SPP illustrates some real-life situations and is often used to assist decision making in the fashion and sporting industries, both at manufacturing and retail levels. The SPP can also be used in managing capacity and booking of orders in service industries such as airlines and hotels [2].

Researchers have followed two approaches for solving the SPP. In the first approach, the expected costs of overestimating and underestimating demand are minimized. In the second approach, the average profit is maximized. Both approaches yield the same results.

Publication of more than 40 papers since 1988 shows an increasing interest on SPP and has provided a wide literature on this subject matter. A partial review of this literature has been recently conducted in a textbook by Silver et al [3].

DOI : $10.5121 /$ ijctcm.2012.2202 
The SPP has a wide use especially in service industries which forms a great part of the US economy. As product life cycles continue with their downward trend, the importance of the SPP grows. Perhaps, this is the main reason that many SPP extensions have been suggested in the recent years. In an overall view, extensions to the SPP can be classified into 11 categories [4]:

(1) Extensions to different objectives and utility functions;

(2) Extensions to different supplier pricing policies;

(3) Extensions to different news-vendor pricing policies and discounting structures;

(4) Extensions to random yields;

(5) Extensions to different states of information about demand;

(6) Extensions to constrained multi-product;

(7) Extensions to multi-product with substitution;

(8) Extensions to multi-echelon systems;

(9) Extensions to multi-location models;

(10) Extensions to models with more than one period to prepare for the selling season; and

(11) Other extensions.

There are a number of multi-echelon extensions to SPP and some of these extensions will be reviewed in this research project. Extensions presented in this article can also be classified in the category of multi-echelon systems.

Gerchak and Henig formulated a single period model for selecting optimal component stock levels in an assemble-to-order system. For a given component stock level, Gerchak and Henig determined the revenue maximization allocation of common components between products. This information is in turn used to select the optimal stock levels [5].

Jonsson and Silver also worked on assemble-to-order environment where some of the components are unique to specific end items, while others are common to two or more end items. Jonsson and Silver assumed that components must be ordered before demands for end items become known. At this time, demands for end items are normally distributed and their values are known before final assembly operations are begun. Jonsson and Silver addressed the problem of deciding on component quantities under a budget constraint so as to maximize the expected number of units of sold end items [6].

Jonsson \& Silver developed their earlier model to deal with many components and end items. They formulated the problem as a two-stage stochastic programming problem with a recourse which turns out to be extremely difficult to find an optimal solution. Jonsson and Silver developed three heuristics for solving the problem under some simplifying assumptions [7]. Jonsson, Jornsten, and Silver used scenario aggregation technique for solving the two-stage stochastic programming problem formulated by Jonsson and Silver. The basic idea behind this scenario aggregation technique is to consider only a relatively small subset of the typically large number of stochastic demand outcomes. For each subset, the optimal values of the decision variables can be easily found. Scenario aggregation ensures that an implementable solution is then obtained using an iterative scheme. Jonsson found that in $50 \%$ of the problems studied, scenario aggregation identified the optimal solution [8].

Gerchak and Zhang developed a two-echelon SPP in which decisions have to be made on whether to hold inventories in the form of raw material or finished products. Holding raw material is less costly but if demand turns out to be high then a fraction of demand is lost since some customers might not be willing to wait for the conversion of raw materials into finished goods. Gerchak and Zhang assumed that there is an initial inventory at both stages and derived the average profit as a 
function of the inventory levels and proved its concavity. Gerchak and Zhang then obtained the optimal inventory policy [9].

Eynan and Rosenblatt also generalized Gerchak and Zhang's model. Eynan and Rosenblatt used the SPP to evaluate an assembly in advance (AIA) versus assemble to order (ATO) strategies in a two-echelon production system [10].

Moon and Choi developed Eynan and Rosenblatt's model to the distribution free case where only the mean and standard deviation of the demands are known. Moon and Choi assumed that there are no initial inventories and all customers will wait for the conversion process. Moon and Choi also treated the problem under a budget constraint using the Lagrange method [11].

In the previous single period models with two different material inventory levels, there are no scraps or defective parts in production process at the beginning or during of the period. This paper presents a novel single period model with two different inventory levels which investigates the problem of scraps or defective products. In proposed model, defective products result in either perfect or scrap products.

\section{Model Analysis}

Classica multi-stage model was studied by Johnson and Montgomery [1]. Here, we consider a single period production model with the possibility of having scraps and rework. In this model, we assume that demand will take place in a short period, and demand is a random variable with density function $f(D)$. Because of the short length of the selling period, there is no opportunity for the manufacturer to reorder raw material from his supplier.

At the start of the period, he has an amount, say $\mathrm{X}_{1}$, in his material inventory and an amount, $\mathrm{X}_{2}$ in his finished product inventory, ready for sale. If he runs out of finished stock during the period, a part of subsequent customers, $\alpha$, will have to wait for production of finished items from stock of raw material. Obviously, the remainder will cancel their orders. After the completion of production process -either at the start or during of period -all finished products are investigated and there is a probability that a finished product is defective or scrap. The defective items are sent to rework process as shown in Figure 1. In the rework process, the defective products may turn into perfect products or scrap.

In the rework process, there is a probability that some products are recognized as defective. These defective products are assumed to be incorrigible and they will be cast away as scrap. Products or raw material remaining at the end of the period must be disposed of. The problem is to determine values for $X_{1}$ and $X_{2}$, in the situation that the average profit in each period is maximized.

\subsection{Assumptions}

The assumptions of proposed model are described as follows:

- Demand is a random variable with the density function $f(D)$;

- Demand will take place only in a short period of time;

- Material and finished products have disposal values at the end of the period;

- All parts are investigated for the possible defects after the production and rework;

- Those defective products recognized as curable undergo a rework process;

- Investigation costs are assumed to be a part of production or rework process costs; 
- Defective products will go through the rework process only once. There is a probability of defectiveness after the rework process;

- Rework process will start just at the end of the production stage;

- Following parameters are supposed to be known and fixed:

- The probability of one product unit produced at the start of the period being scrap $(\omega)$

- The probability of one product unit produced during the period being scrap $(\gamma)$

- The probability of one product unit produced at the start of the period being curable $(\eta)$

- The probability of one product unit produced during the period being curable $(\beta)$

- The probability of one product unit turning into scrap after rework at the beginning of the period $(v)$

- The probability of one product unit turning into scrap after the rework during the period $(\lambda)$;

- Cost of one unit of finished product equals the sum of cost of buying one unit of raw material and cost of producing one unit of finished product; and

- Unit selling price of finished product is fixed.

There is no difference between the unit selling prices of reworked and non-reworked products.

\subsection{Notation}

We define the following notations for the mathematical model:

$X_{1}$ : Material inventory at the start of the period, a decision variable;

$X_{2}$ : Finished product inventory at the start of the period, a decision variable;

$C_{1}$ : Cost per unit of material inventory at the start of the period;

$C_{2}$ : Cost of processing a unit of material into a unit of finished product;

$C_{3}$ : Cost of rework for each unit of defective finished product during the period;

$C_{4}$ : Cost of rework for each unit of defective finished product at the start of the period;

$L_{l}$ : Disposal value per unit of material inventory at the end of the period;

$L_{2}$ : Disposal value per unit of finished product inventory at the end of the period;

$D$ : Quantity of demand, a random variable;

$f(D)$ : The probability density functions of demand;

$\alpha$ : Part of customers who wait for manufacturer to produce their demand from his available inventory of material;

$r$ : Unit selling price of finished product;

$\eta$ : The probability of one product unit produced at the start of the period being curable, $0<\eta<1$;

$\omega$ : The probability of one product unit produced at the start of the period being scrap, $0<\omega<1$;

$v$ : The probability of one product unit turning into scrap after the rework at the beginning of the period, $0<v<1$ and $0<1-\omega-\eta \nu<1$;

$\beta$ : The probability of one product unit produced during the period being curable, $0<\beta<1$;

$\gamma: \quad$ The probability of one product unit produced during the period being scrap, $0<\gamma<1$;

$\lambda$ : The probability of one product unit turning into scrap after the rework during the period, $0<\lambda<1$ and $0<1-\gamma-\beta \lambda<1$;

$V\left(D, X_{1}, X_{2}\right)$ : profit function in each period;

$\bar{V}\left(D, X_{1}, X_{2}\right)$ : average profit function in each period;

We assume that for this model $L_{2}<L_{1}<C_{1}$ and also $L_{2}<C_{1}+C_{2}+C_{3} \beta<r(1-\gamma-\beta \lambda)$. These last assumptions are quiet reasonable considering the environment of the problem. 
International Journal of Control Theory and Computer Modelling (IJCTCM) Vol.2, No.2, March 2012

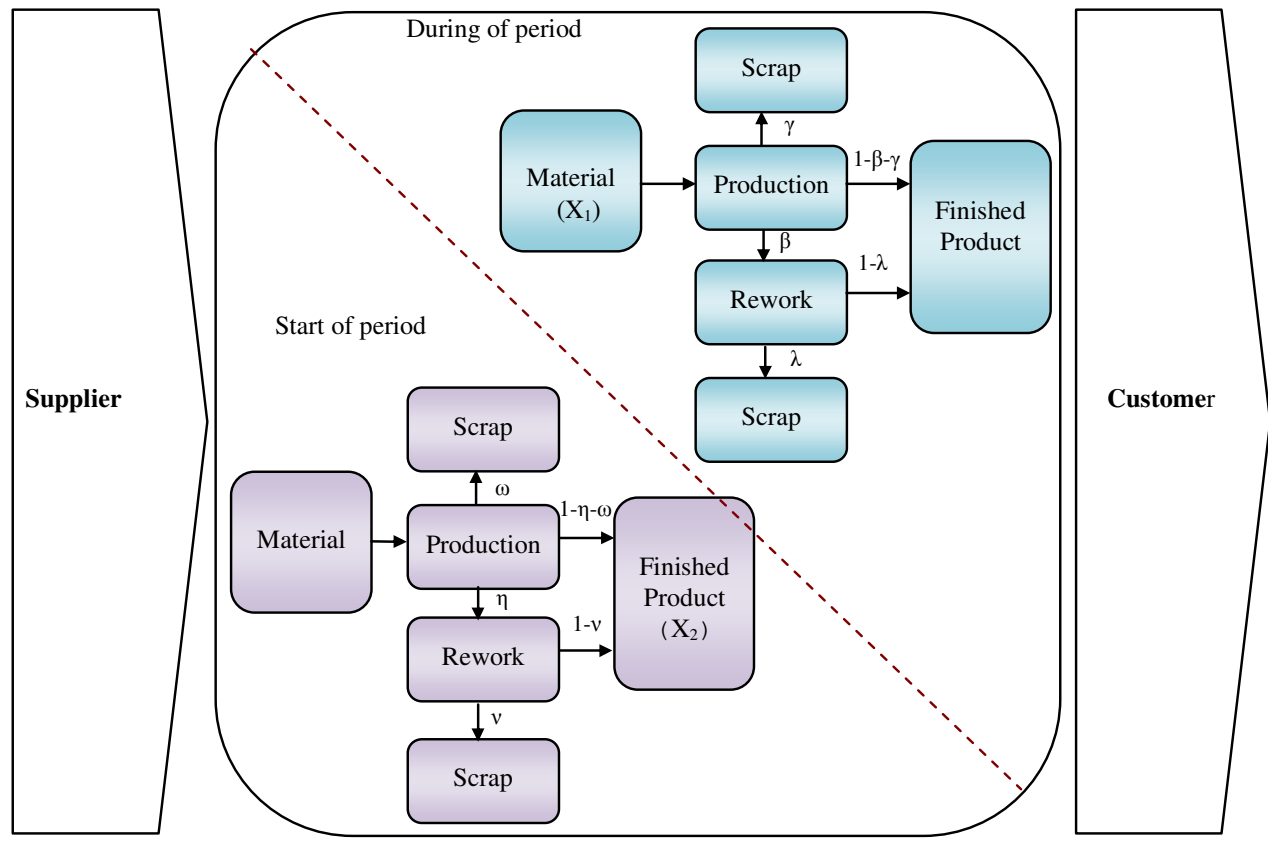

Figure 1. Schematic diagram of single period production problem with scrap and rework at the beginning and during of period

\subsubsection{First situation}

In the first situation, the value of the demand variable is less than the units of procured finished product at the start of the period (Figure 2). Obviously, in this case, manufacturer does not need to produce more items using the raw material and the inventory of finished products can satisfy the whole demand. Therefore, at the end of period all unsold units and raw material will be sold for the determined disposal value. This means that $0 \leq D \leq X_{2}$.

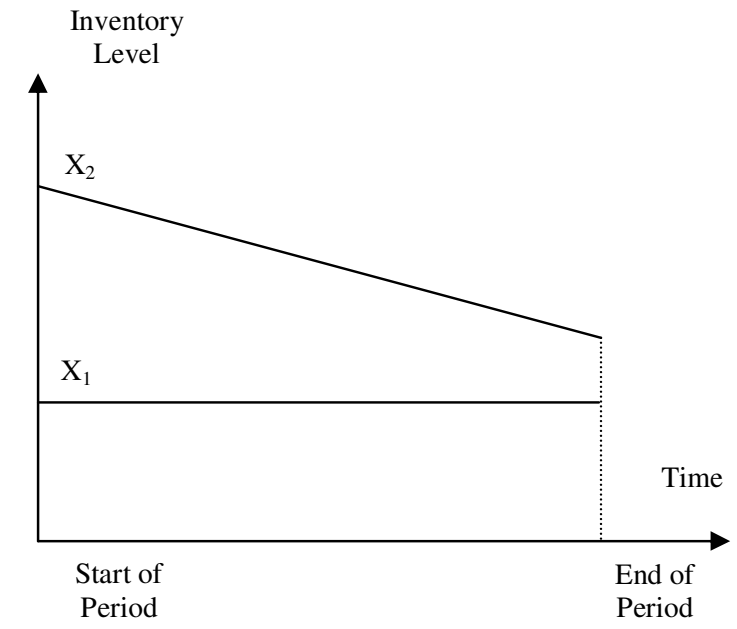

Figure 2. Inventory level during the period in the first situation

Therefore the profit function would be: 


$$
V_{1}\left(D, X_{1}, X_{2}\right)=D\left[r-L_{2}\right]+X_{1}\left[L_{1}-C_{1}\right]+X_{2}\left[L_{2}-\frac{\left(C_{1}+C_{2}+C_{4} \eta\right)}{(1-\omega-\eta v)}\right]
$$

\subsubsection{Second situation}

In the second situation, the amount of demand is more than the amount of finished products at the start of period (Figure 3). Consequently, shortage will occur and a number of customers will wait for the manufacturer to produce finished products while the remainder will cancel their orders. In addition, the demand is not as high as it requires all the raw material to change into finished products. Hence, the remaining raw material will be sold for the determined disposal value. This means that $X_{2}<D \leq \frac{(1-\gamma-\beta \lambda)}{\alpha} X_{1}+X_{2}$.

$$
\text { Inventory Level }
$$

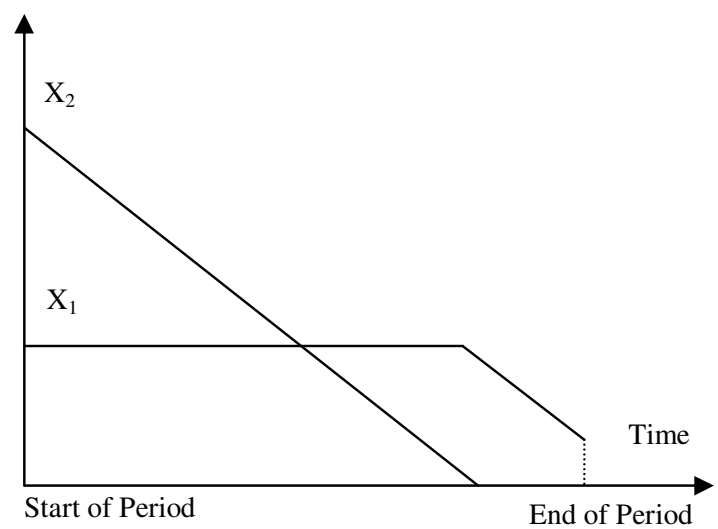

Figure 3. Inventory level during the period in the second situation

Therefore the profit function would be:

$$
\begin{aligned}
& V_{2}\left(D, X_{1}, X_{2}\right)=D\left[r \alpha-\frac{L_{1} \alpha}{(1-\gamma-\beta \lambda)}-\frac{C_{2} \alpha}{(1-\gamma-\beta \lambda)}-\frac{C_{3} \alpha \beta}{(1-\gamma-\beta \lambda)}\right]+X_{1}\left[L_{1}-C_{1}\right] \\
& +X_{2}\left[\begin{array}{l}
r(1-\alpha)-\frac{\left(C_{1}+C_{2}+C_{4} \eta\right)}{(1-\omega-\eta \nu)}+\frac{L_{1} \alpha}{(1-\gamma-\beta \lambda)}+\frac{C_{2} \alpha}{(1-\gamma-\beta \lambda)} \\
+\frac{C_{3} \alpha \beta}{(1-\gamma-\beta \lambda)}
\end{array}\right]
\end{aligned}
$$

\subsubsection{Third situation}

Lastly, in the third situation, the value of the demand variable is more than the sum of amounts of in-stock material and finished product procured at the beginning of period. Therefore, the manufacturer needs to send all available in-stock raw materials to the production stage (Figure 4). In other words, $\frac{(1-\gamma-\beta \lambda)}{\alpha} X_{1}+X_{2}<D$. 


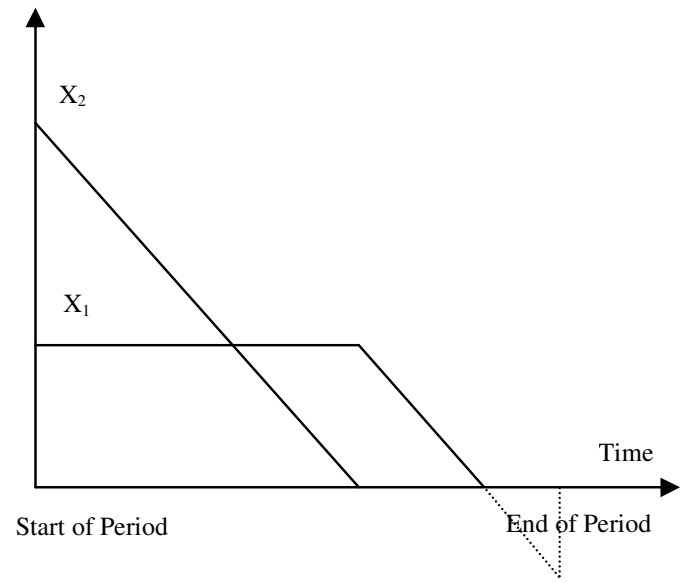

Figure 4. Inventory level during the period in the third state

Profit function in this case is:

$V_{3}\left(D, X_{1}, X_{2}\right)=X_{1}\left[r(1-\gamma-\beta \lambda)-C_{1}-C_{2}-C_{3} \beta\right]+X_{2}\left[r-\frac{\left(C_{1}+C_{2}+C_{4} \eta\right)}{(1-\omega-\eta \nu)}\right]$

According to the equations (1), (2), and (3), the average profit function would be:

$$
\begin{aligned}
& \bar{V}\left(D, X_{1}, X_{2}\right)=\int_{0}^{X_{2}} V_{1}\left(X_{1}, X_{2}, D\right) f(D) d D+\int_{X_{2}}^{\frac{(1-\gamma-\beta \lambda)}{\alpha} X_{1}+X_{2}} V_{2}\left(X_{1}, X_{2}, D\right) f(D) d D \\
& +\int_{\frac{(1-\gamma-\beta \lambda)}{\alpha} X_{1}+X_{2}}^{\infty} V_{3}\left(X_{1}, X_{2}, D\right) f(D) d D
\end{aligned}
$$

\section{OPTIMAL SOLUTION}

The following problem is a non-linear unconstrained problem with the general form of:

$$
\begin{aligned}
& M A X \bar{V}\left(D, X_{1}, X_{2}\right) \\
& X_{1}, X_{2}>0
\end{aligned}
$$

We need to check sufficient conditions to find the optimal solution [12]. The Gradient matrix of the average profit function is as follows:

$$
\nabla \bar{V}\left(D, X_{1}, X_{2}\right)=\left[\begin{array}{l}
\frac{\partial \bar{V}}{\partial X_{1}} \\
\frac{\partial \bar{V}}{\partial X_{2}}
\end{array}\right]=0 \Rightarrow \frac{\partial \bar{V}}{\partial X_{1}}=0, \frac{\partial \bar{V}}{\partial X_{2}}=0
$$

Using Leibniz Integral Theorem, partial derivatives are [13]: 


$$
\begin{aligned}
& \frac{\partial \bar{V}}{\partial X_{1}}=\left[r(1-\gamma-\beta \lambda)-C_{1}-C_{2}-C_{3} \beta\right] \\
& -F\left(\frac{(1-\gamma-\beta \lambda)}{\alpha} X_{1}+X_{2}\right)\left[r(1-\gamma-\beta \lambda)-L_{1}-C_{2}-C_{3} \beta\right]=0
\end{aligned}
$$

Finally, we have the following statement:

$$
F\left(\frac{(1-\gamma-\beta \lambda)}{\alpha} X_{1}^{*}+X_{2}^{*}\right)=\frac{\left[r(1-\gamma-\beta \lambda)-C_{1}-C_{2}-C_{3} \beta\right]}{\left[r(1-\gamma-\beta \lambda)-L_{1}-C_{2}-C_{3} \beta\right]}
$$

In accordance with Leibniz theorem, the other partial derivative of the average profit function can be calculated as:

$$
\begin{aligned}
& \frac{\partial \bar{V}}{\partial X_{2}}=r-\frac{\left(C_{1}+C_{2}+C_{4} \eta\right)}{(1-\omega-\eta v)}+\left[L_{2}-r(1-\alpha)-\alpha \frac{\left(L_{1}+C_{2}+C_{3} \beta\right)}{(1-\gamma-\beta \lambda)}\right] F\left(X_{2}\right) \\
& -\left[\frac{\alpha}{(1-\gamma-\beta \lambda)}\left(r(1-\gamma-\beta \lambda)-\left(L_{1}+C_{2}+C_{3} \beta\right)\right)\right] F\left(\frac{(1-\gamma-\beta \lambda)}{\alpha} X_{1}+X_{2}\right)=0
\end{aligned}
$$

Then, according to the equation (8), the value of the cumulative distribution function at the extremum point could be written as follows and can be calculated based on the demand's distribution function.

$$
F\left(X_{2}^{*}\right)=\frac{\left[r(1-\gamma-\beta \lambda)(1-\alpha)-\left(\frac{(1-\gamma-\beta \lambda)}{(1-\omega-\eta \nu)}-\alpha\right)\left(C_{1}+C_{2}\right)+C_{3} \alpha \beta-C_{4} \eta \frac{(1-\gamma-\beta \lambda)}{(1-\omega-\eta \nu)}\right]}{\left[r(1-\gamma-\beta \lambda)(1-\alpha)+\alpha C_{2}+\alpha L_{1}-L_{2}(1-\gamma-\beta \lambda)+C_{3} \alpha \beta\right]}
$$

Based on the above calculations, the point $X=\left(X_{1}, X_{2}\right)$ is a local extremum. We need to check the sufficient condition for $X$ as well as proving the concavity of the objective function in order to show that $\mathrm{X}$ is also a global extremum. To prove the concavity, we calculate the Hessien matrix by defining $\mathrm{M}$ and $\mathrm{N}$ as follows:

$$
\begin{aligned}
& M=X_{2} \\
& N=\frac{(1-\gamma-\beta \lambda)}{\alpha} X_{1}+X_{2}
\end{aligned}
$$

Hessien matrix for this problem is calculated as follows:

$$
\nabla^{2} \bar{V}\left(D, X_{1}, X_{2}\right)=\left[\begin{array}{cc}
\frac{\partial^{2} \bar{V}}{\partial X_{1}^{2}} & \frac{\partial^{2} \bar{V}}{\partial X_{1} \partial X_{2}} \\
\frac{\partial^{2} \bar{V}}{\partial X_{1} \partial X_{2}} & \frac{\partial^{2} \bar{V}}{\partial X_{2}^{2}}
\end{array}\right]
$$


International Journal of Control Theory and Computer Modelling (IJCTCM) Vol.2, No.2, March 2012

$$
=\left[\begin{array}{cc}
-\left[\begin{array}{l}
r(1-\gamma-\beta \lambda) \\
-L_{1}-C_{2}-C_{3} \beta
\end{array}\right]\left(\frac{(1-\gamma-\beta \lambda)}{\alpha}\right) f(N) & -\left[\begin{array}{l}
r(1-\gamma-\beta \lambda) \\
-L_{1}-C_{2}-C_{3} \beta
\end{array}\right] f(N) \\
-\left[\begin{array}{l}
r(1-\gamma-\beta \lambda) \\
-L_{1}-C_{2}-C_{3} \beta
\end{array}\right] f(N) & -\left(\frac{\alpha}{(1-\gamma-\beta \lambda)}\right)\left[\begin{array}{l}
\left(r(1-\alpha)-L_{2}\right)(1-\gamma-\beta \lambda) \\
\alpha \\
+L_{1}+C_{2}+C_{3} \beta \\
+\left(\begin{array}{l}
r \\
(1-\gamma-\beta \lambda) \\
-L_{1}-C_{2}-C_{3} \beta
\end{array}\right) f(N)
\end{array}\right]
\end{array}\right]
$$

To check the concavity of the average profit function, one should multiply its entries by (-1). Since the Hessien matrix is $2 \times 2$, we must check the positivity of the determinant for upper left corner of $1 \times 1$ matrix as well as the determinant of the whole matrix. By proving the positivity of the mentioned determinants, the concavity of the function follows and the local extremum will prove to be global extremum [14].

$$
\nabla^{2} \bar{V}\left(D, X_{1}, X_{2}\right)=\left[\begin{array}{cc}
\frac{\partial^{2} \bar{V}}{\partial X_{1}^{2}} & \frac{\partial^{2} \bar{V}}{\partial X_{1} \partial X_{2}} \\
\frac{\partial^{2} V}{\partial X_{1} \partial X_{2}} & \frac{\partial^{2} \bar{V}}{\partial X_{2}^{2}}
\end{array}\right]
$$

According to the definition of $\mathrm{M}$ and $\mathrm{N}$, for the first entry of the matrix, $\frac{\partial^{2} \bar{V}}{\partial X_{1}^{2}}$, we have:

$\left[r(1-\gamma-\beta \lambda)-L_{1}-C_{2}-C_{3} \beta\right]\left(\frac{(1-\gamma-\beta \lambda)}{\alpha}\right) f(N)>0$

$f(N)$ and $\left(\frac{(1-\gamma-\beta \lambda)}{\alpha}\right)$ are always positive. Therefore, based on the problems' assumptions, the following statement is always positive:

$$
\left[r(1-\gamma-\beta \lambda)-L_{1}-C_{2}-C_{3} \beta\right]>0
$$

The determinant of the whole matrix can be written as:

$$
\begin{aligned}
& {\left[r(1-\gamma-\beta \lambda)-L_{1}-C_{2}-C_{3} \beta\right] f(N)\left[\begin{array}{l}
\left(\frac{\left(r(1-\alpha)-L_{2}\right)(1-\gamma-\beta \lambda)}{\alpha}+L_{1}+C_{2}+C_{3} \beta\right) f(M) \\
+\left(r(1-\gamma-\beta \lambda)-L_{1}-C_{2}-C_{3} \beta\right) f(N)
\end{array}\right]} \\
& -\left[r(1-\gamma-\beta \lambda)-L_{1}-C_{2}-C_{3} \beta\right]^{2} f^{2}(N)
\end{aligned}
$$

After some simplifications, we can write the determinant of the whole matrix as follows. By assumptions of the problem, we know that the below inequality always holds:

$$
\frac{(1-\gamma-\beta \lambda)\left(r-L_{2}\right)}{\alpha}>\left[r(1-\gamma-\beta \lambda)-L_{1}-C_{2}-C_{3} \beta\right]>0
$$

Hence, we can conclude that the determinant of the whole matrix is always positive. This sequence results in concavity of average profit function. Therefore, one can find the optimal solution using equations (8) and (10). Also, if the value of $\beta, \gamma, \lambda, \eta, \omega, v$ equal to zero, the optimal solution of classic model can be obtained [1]. 


\section{NUMERICAL EXAMPLES}

In order to check the validity of the proved results in the proposed model, some numerical examples are brought and then, results are compared.

Here, there are a number of assumptions: first, selling price of each unit of the finished product at the end of the period is $\$ 100$. Second, purchase of raw material costs $\$ 30$ for each unit and purchase price of each unit of finished product at the start of the period is $\$ 40$. Third, disposal prices at the end of the period are $\$ 20$ for each unit of the raw material and $\$ 10$ for each unit of finished product. Now, assume that the fraction of the costumers who wait for the manufacturer to provide them with their orders in case of shortage is 0.4 . Demand is a Normal random variable which takes place during one period [1].

$r=100 \$, \mathrm{C} 1=30 \$, \mathrm{C} 2=40 \$, \mathrm{~L} 1=20 \$, \mathrm{~L} 2=10 \$, \alpha=0.4$

For the proposed model, with the probability of 0.1 , assume that the production stage will result in production of a unit of product which is curable by rework. Similarly, with the probability of 0.05 , assume that it will result in production of an incurable product. Furthermore, the probability of having scrap at the end of rework stage is 0.1 and rework costs $\$ 45$ for each unit of curable finished product. All these assumptions are both at the start and during the period.

$\beta=\eta=0.1, \gamma=\omega=0.05, \lambda=v=0.1, C_{3}=C_{4}=45 \$$

In the first example, if we assume that demand is a Normal random variable with the mean of 1000 and standard deviation of 200, based on the equations (8) and (10) we have:

$$
F\left(X_{2}^{*}\right)=0.16, F\left(X_{2}^{*}+2.35 X_{1}^{*}\right)=0.66
$$

Simply, by using Normal distribution table, we have following results:

$$
\begin{aligned}
& X_{2}^{*}=801.69 \\
& X_{1}^{*}=119.72
\end{aligned}
$$

$X_{1}^{*}, X_{2}^{*}$ represent the optimum amounts for procurement of raw material and production of finished products at the start of the period.

According to the equation (4), and considering standard Normal distribution table, optimum average profit function, denoted by $\bar{V}_{\text {Proposed }}^{*}\left(D, X_{1}^{*}, X_{2}^{*}\right), X(119.72,801.69)$ is calculated below:

$$
\begin{aligned}
& \bar{V}_{\text {Proposed }}^{*}(D, 119.72,801.69)=\int_{0}^{801.69} 90 D f(D) d D-567189[F(801.69)-F(0)] \\
& +\int_{801.69}^{1083.04} 12.5 f(D) d D+5369.83[F(1083.04)-F(801.69)]+18965.5[1-F(1083.04)]=160461
\end{aligned}
$$

If we overlook the possibility of scrap and rework both at the beginning and during the period, by using the classical newsvendor model, we will have $X_{1}=109, X_{2}=862$. This solution results in the equation (4) as follows: 
International Journal of Control Theory and Computer Modelling (IJCTCM) Vol.2, No.2, March 2012

$$
\begin{aligned}
& \bar{V}_{\text {Proposed }}(D, 109,862)=\int_{0}^{862} 90 D f(D) d D-607881[F(862)-F(0)] \\
& \left.+\int_{862}^{1112.55 D f(D) d D+5971.06[F(862)}-F(1118.15)\right]+20007.04[1-F(1118.15)]=15843.56
\end{aligned}
$$

If we use classical model solution, we would have a reduction of 202.53 units in profit.

For this solution, optimum profit using the classic model's objective function, denoted by $\bar{V}_{\text {Classic }}^{*}\left(D, X_{1}, X_{2}\right), X(109,862)$ will be:

$$
\begin{aligned}
& \bar{V}_{\text {Classic }}^{*}(D, 109,862)=\int_{0}^{862} 90 D f(D) d D-52810[F(862)-F(0)] \\
& +\int_{862}^{1134.5} 16 D f(D) d D+10978[F(1134.5)-F(862)]+29130[1-F(1134.5)]=24348.47
\end{aligned}
$$

In case that there is a rework stage and scraps, profit would reduce if we neglect them and use the solution obtained by the classic model. The lost profit would be:

$$
\Delta \bar{V}=\bar{V}_{\text {Classic }}^{*}(D, 109,862)-\bar{V}_{\text {Pr } \text { oposed }}(D, 109,862)=24348.47-15843.56=8504.91
$$

Difference between optimum profits is shown below:

$$
\Delta \bar{V}=\bar{V}_{\text {Classic }}^{*}(D, 109,862)-\bar{V}_{\text {Proposed }}^{*}(D, 119.72,801.69)=24348.47-16046.1=8302.37
$$

Even in optimum situations, having scraps and rework may cause a reduction of about 8302.37 in profit, compared to the ideal production system. These results would help managers to make appropriate decisions on replacing or correcting the machines or technologies. Disregarding hidden costs like those of rework and scrap reduces the profit and results in increased costs.

Above results are obtained from some other numerical examples with the outcomes summarized in table 1 . In these examples, the parameters of Normal random variable $(\mu, \sigma)$ are changed and other parameters are same as first example.

Table 1. Numerical results

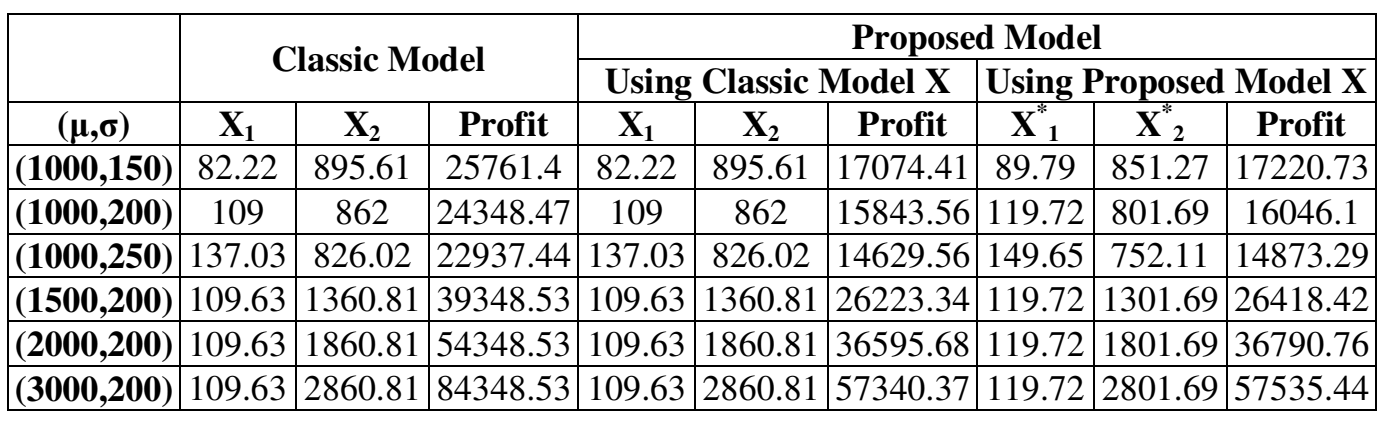

Indeed, the proposed model is able to present real situations more accurately in comparison to the classic model. This is mainly because it includes rework and scrap costs both at the beginning and during the period. 


\section{SENSITIVITY ANALYSIS}

In order to analyze the sensitivity of proposed model, some parameters are changed and then, effects of this change on the obtained solution $\left(\mathrm{X}_{1}, \mathrm{X}_{2}\right)$ and expected profit are studied. These parameters are $\beta, \gamma, \lambda, \eta, \omega, v$ and others are same as first numerical example parameters. In addition, in every analysis, there are two parameters increasing together from 0 to 1 with 0.01 change in each step. Meanwhile, the results, shown in the graph below, are feasible solution of proposed model according to its assumptions.

According to these results, when variant parameters increase from 0 to 1 , the raw material inventory $\left(\mathrm{X}_{1}\right)$ remains approximately constant. However, finished product inventory $\left(\mathrm{X}_{2}\right)$ gradually reduces. These results show $X_{2}$ is more sensitive than $X_{1}$ by changing variant parameters.

So, the graph below shows the trend of expected profit by changing $(\beta, \eta),(\gamma, \omega)$, and $(\lambda, \nu)$. This graph shows that the expected profit is so sensitive and dramatically falls by increasing these parameters.

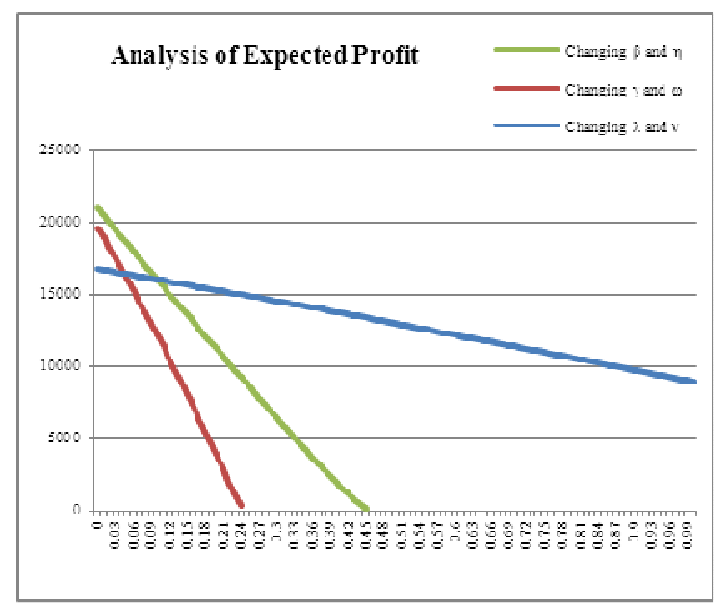

Figure 5. Analysis of expected profit

Also, the reduction of profit is more sensitive by increasing the probability of producing scrap items in comparison to the probability of producing defective items.

\section{CONCLUSION}

In this paper, a specific case of the single period model is studied and single period production models are developed by considering the probability of producing defective products and scraps at the start and during of period. Then, optimum solution is calculated and shown.

According to the numerical results and by considering the probability of producing defective products and scraps, it is shown that using the proposed model increases the average profit in comparison to that of the classic model. On the other hand, this model shows that the by increasing the probability of producing defective products or scraps, the amount of average profit decreases. 
International Journal of Control Theory and Computer Modelling (IJCTCM) Vol.2, No.2, March 2012

Rsults of comparison between the quantities of optimum profit in classical model and proposed model would help managers to make appropriate decisions on replacing or revising machines or technologies.

After all, the results of sensitive analysis show the raw material inventory is less sensitive than the finished product inventory by changing $\beta, \gamma, \lambda, \eta, \omega, v$. Meanwhile, the expected profit is more sensitive by increasing the probability of producing scrap items in comparison to the probability of producing defective items.

\section{REFERENCES}

[1] Johnson, L. and D. Montgomery, Operations research in production planning, scheduling and inventory control. 1974, New York: Wiley.

[2] Weatherford, L. and P. Pfeifer, The economic value of using advance booking of orders. Omega, 1994. 22(1): p. 105-111.

[3] Silver, E., D. Pyke, and R. Peterson, Inventory management and production planning and scheduling. 1998, New York: Wiley.

[4] Khouja, M., The single-period (news-vendor) problem: literature review and suggestions for future research. Omega 1999. 27(5): p. 537-553.

[5] Gerchak, Y. and D. Henig, An inventory model with component commonality. Operations Research Letters, 1986. 5(3): p. 157-169.

[6] Jonsson, H. and E. Silver, Optimal and heuristic solutions for a simple common component inventory problem. Engineering Costs and Production Economics, 1989. 16(4): p. 257-267.

[7] Jonsson, H. and E. Silver, Common component inventory problem with a budget constraint: heuristics and upper bounds. Engineering Costs and Production Economics 1989. 18(1): p. 71-81.

[8] Jonsson, H., K. Jornsten, and E. Silver, Application of the scenario aggregation approach to a two-stage, stochastic common component, inventory problem with a budget constraint. European Journal of Operation Research 1993. 68(2): p. 196-211.

[9] Gerchak, Y. and X. Zhang, The effect of initial inventories in a two-echelon system. IIE Transactions, 1992. 24(1): p. 64-69.

[10] Eynan, A. and M. Rosenblatt, Assemble to order and assemble in advance in a single period stochastic environment. Naval Research Logistics (NRL), 1995. 42(5): p. 861-872.

[11] Moon, I. and S. Choi, Distribution free procedures for make to-order (MTO), make-in-advance (MIA), and composite policies. International Journal of Production Economics 1997. 48(1): p. 2128.

[12 Boyd, S. and L. Vandenberghe, Convex Optimization. 2004, Cambridge: University Press.

[13] Abramowitz, M. and I. Stegun, Handbook of Mathematical Functions with Formulas, Graphs, and Mathematical Tables. 1972, New York: Dover.

[14] Korkel, S., Optimality Conditions and Constraint Qualifications for Nonlinear Optimization Problems, in Seminar "Convergence Theory for NLP Solvers". 2007, University of Berlin. 
International Journal of Control Theory and Computer Modelling (IJCTCM) Vol.2, No.2, March 2012

\section{Authors}

\section{Fatemeh Charkhsaz}

She is a PhD candidate at the University of Newcastle' School of Mathematical and Physical Sciences since 2011 and has been awarded full scholarship by the University of Newcastle. She received a Bachelor of Science in Industrial Engineering with System Analysis concentration in 2004 and a Master of Science in Industrial Engineering in 2007 from Sharif University of Technology, Tehran, Iran.

\section{Alireza Haji}

$\mathrm{He}$ is an Associate Professor at Industrial Engineering Department, Sharif University of Technology in Tehran, Iran. He received his $\mathrm{PhD}$ in Industrial Engineering from Sharif University of Technology in 2001. His Bachelor and Master of Science degrees are also in Industrial engineering from Sharif University of Technology.
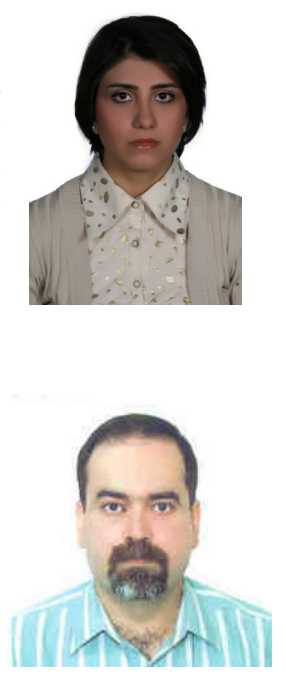